\title{
Icariside II protects cardiomyocytes from hypoxia-induced injury by upregulating the miR-7-5p/BTG2 axis and activating the PI3K/Akt signaling pathway
}

\author{
DONGXIA HU ${ }^{1 *}$, YONG GU ${ }^{2 *}$, DAN WU ${ }^{3}$, JUANJUAN ZHANG ${ }^{1}, \mathrm{QING} \mathrm{LI}^{4}$,

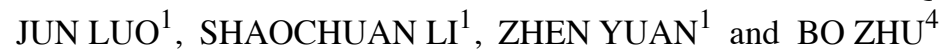 \\ ${ }^{1}$ Department of Rehabilitation, The Second Affiliated Hospital of Nanchang University; ${ }^{2}$ Department of Clinical Laboratory, \\ Jiangxi Thoracic Hospital; ${ }^{3}$ Department of Neurology, Nanchang Hongdu Hospital of TCM; ${ }^{4}$ Department of Cardiology, \\ The Second Affiliated Hospital of Nanchang University, Nanchang, Jiangxi 330321, P.R. China
}

Received November 25, 2019; Accepted March 10, 2020

DOI: $10.3892 /$ ijmm.2020.4677

\begin{abstract}
Icariside II (ICS II) has been reported to have protective effects against oxidative stress. However, whether ICS II protects cardiomyocytes from myocardial infarction (MI), and the associated underlying mechanisms, remain to be elucidated. Therefore, the current study investigated the effects of ICS II on hypoxia-injured H9c2 cells, as well as the associated molecular mechanisms. A hypoxic injury model was established to emulate the effects of MI. The effects of ICS II on the proliferation of rat cardiomyocyte H9c2 cells were assessed with cell counting kit- 8 assays. The apoptotic status of the cells was assessed by flow cytometry, and the expression of apoptosis-related proteins was analyzed by western blotting. A microRNA (miRNA/miR) microarray was used to quantify the differential expression of miRNAs after ICS II treatment, and the levels of miR-7-5p were further quantified by reverse transcription-quantitative PCR. Whether ICS II affected hypoxia-injured cells via miR-7-5p was subsequently examined, and the target of miR-7-5p was also investigated by bioinformatics analysis and luciferase reporter assays. The effects of ICS II on the PI3K/Akt pathway were then evaluated by western blot analysis. Hypoxia treatment decreased viability and the migration and invasion abilities of $\mathrm{H} 9 \mathrm{c} 2$ cells, and also induced apoptosis. ICS II significantly increased viability and reduced hypoxia-associated apoptosis. Moreover, ICS II treatment led to the upregulation of miR-7-5p, and the protective effects of ICS II were found to rely on miR-7-5p. Moreover, BTG anti-proliferation factor (BTG2) was identified as a direct
\end{abstract}

Correspondence to: Dr Bo Zhu, Department of Cardiology, The Second Affiliated Hospital of Nanchang University, 1 Mingde Road, Nanchang, Jiangxi 330321, P.R. China

E-mail: zhubo32146@126.com

${ }^{*}$ Contributed equally

Key words: icariside II, hypoxia, cardiomyocyte, microRNA-7-5p, BTG anti-proliferation factor 2, PI3K/Akt target of miR-7-5p, and overexpression of BTG2 inhibited the protective effects of miR-7-5p. Finally, ICS II treatment resulted in the activation of the PI3K/Akt signaling pathway, which is essential for the survival of $\mathrm{H} 9 \mathrm{c} 2$ cells under hypoxic conditions. In summary, ICS II reduces hypoxic injury in $\mathrm{H} 9 \mathrm{c} 2$ cells via the miR-7-5p/BTG2 axis and activation of the $\mathrm{PI} 3 \mathrm{~K} /$ Akt signaling pathway.

\section{Introduction}

Myocardial infarction (MI) as a result of cardiovascular diseases is a leading cause of death and disability worldwide (1). MI caused by temporary or permanent occlusion of the main coronary arteries may lead to a reduction in the blood supply to the cardiac muscle (2). Significant levels of cardiomyocyte apoptosis are an important physiological feature of MI, which can be triggered by hypoxia (3). Ultimately, MI may promote heart failure due to decreased contraction of the myocardium (4). Although the treatment of MI has markedly improved, the mortality and morbidity rates are still far from satisfactory (5). Therefore, the identification of potential therapeutic agents against MI, as well as the elucidation of its underlying mechanisms, is critical.

Icariside II (ICS II) is a flavonol glycoside that can be isolated from Herba Epimedii, which has commonly been used in Traditional Chinese Medicine for thousands of years (6). ICS II has been reported to possess anti-inflammatory, antitumor and anti-osteoporotic properties (7). In recent years, ICS II has been found to exert various cardioprotective effects, such as the alleviation of myocardial fibrosis and diabetic cardiomyopathy $(8,9)$. However, the specific roles and related molecular mechanisms of ICS II in hypoxia-induced $\mathrm{H} 9 \mathrm{c} 2$ cells remain elusive.

MicroRNAs (miRNAs/miRs) are a group of endogenous, noncoding small RNAs that play important roles in numerous pathological and physiological processes (10). Accumulating evidence has revealed that miRNAs play an essential role in the pathophysiological consequences of MI $(11,12)$, and several potential agents isolated from herbs have been found to exert their pharmacological activities through the 
regulation of miRNAs $(13,14)$. miR-7-5p is a multifaceted miRNA that participates in the development of various types of cancer (15). It is also able to protect cardiomyocytes against ischemia/reperfusion (I/R) injury by targeting Poly [ADP-ribose] polymerase 1 (16). However, whether miR-7-5p is also involved in regulating the functions of ICS II in MI was previously unknown.

In the current study, $\mathrm{H} 9 \mathrm{c} 2$ rat cardiomyocytes were cultured under hypoxic conditions to produce an MI injury model. Then, the effects of ICS II on the hypoxia-induced injury of $\mathrm{H} 9 \mathrm{c} 2$ cells, and its possible molecular mechanisms, were investigated. The results indicate that ICS II protects $\mathrm{H} 9 \mathrm{c} 2$ cells from hypoxia-induced injury via the regulation of the miR-7-5/BTG anti-proliferation factor (BTG2) axis and the $\mathrm{PI} 3 \mathrm{~K} /$ Akt signaling pathway.

\section{Materials and methods}

Cell culture and treatment. Rat cardiomyocyte H9c2 cells were purchased from the American Type Culture Collection. H9c2 cells were maintained in DMEM (Thermo Fisher Scientific, Inc.) with $10 \%$ fetal bovine serum, $100 \mathrm{U} / \mathrm{ml}$ penicillin and $100 \mu \mathrm{g} / \mathrm{ml}$ streptomycin (all Gibco; Thermo Fisher Scientific, Inc.) at $37^{\circ} \mathrm{C}\left(5 \% \mathrm{CO}_{2}\right)$ in a humidified atmosphere. To establish the hypoxia-induced injury model, cells were exposed to hypoxic conditions $\left(93 \% \mathrm{~N}_{2}, 2 \% \mathrm{O}_{2}\right.$ and $5 \% \mathrm{CO}_{2}$ ) for $24 \mathrm{~h}$; cells incubated under normoxic conditions $\left(95 \%\right.$ air and $5 \% \mathrm{CO}_{2}$ ) were used as a control. ICS II (purity $>98 \%$ by HPLC) was purchased from Nanjing Zelang Medical Technology Corporation Ltd. ICS II was dissolved in DMSO (Sigma-Aldrich; Merck KGaA) to a concentration of $10 \mathrm{mM}$ and stored at $-80^{\circ} \mathrm{C}$. ICS II was diluted with complete medium to achieve the different designated concentrations. Cells were treated with different concentrations of ICSII (2, 4 and $8 \mu \mathrm{M}$ ) at $37^{\circ} \mathrm{C}$ for $24 \mathrm{~h}$, and then subjected to different types of analysis. LY294002 (Sigma-Aldrich; Merck KGaA), an inhibitor of the PI3K/Akt pathway, was stored at $-20^{\circ} \mathrm{C}$ and diluted in complete medium at a final concentration of $10 \mu \mathrm{M}$. Where appropriate, cells were co-treated with LY294002 $(10 \mu \mathrm{M})$ and ICSII $(8 \mu \mathrm{M})$ at $37^{\circ} \mathrm{C}$ for $24 \mathrm{~h}$, and subsequently analyzed experimentally. The same concentration of DMSO was applied to cells as a control. All other routine chemicals were obtained from Sigma.

Transfection. miR-7-5p mimics, miR-7-5p inhibitor and a negative control miR (NC) were all synthesized by Suzhou GenePharma Co., Ltd and used at a concentration of $100 \mathrm{nM}$. The full-length BTG2 sequence was inserted into a pcDNA 3.1 plasmid (Suzhou GenePharma Co., Ltd.), and the empty vector was used as a negative control. The cells were transfected with the corresponding vectors using Lipofectamine ${ }^{\circledR} 2000$ (Thermo Fisher Scientific, Inc.) according to the manufacturer's instructions. Reverse transcription-quantitative (RT-q) PCR and western blot analysis were performed to determine transfection efficacy. Subsequent experimentation was performed $24 \mathrm{~h}$ after the transfection.

Cell viability assay. The Cell Counting Kit-8 (CCK-8; Beijing Solarbio Science \& Technology Co., Ltd.) was used to assess cell viability according to the manufacturer's protocol.
H9c2 cells were seeded into 96-well plates at a density of $5 \times 10^{3}$ cells/well and cultured at $37^{\circ} \mathrm{C}$ overnight. The cells were then cultured under hypoxic conditions for $24 \mathrm{~h}$ (as aforementioned), which was followed by a further 24-h incubation at $37^{\circ} \mathrm{C}$ under normoxic conditions. After reoxygenation, $10 \mu \mathrm{l}$ CCK-8 solution was added to each well, followed by a 4-h incubation period. The absorbance at $450 \mathrm{~nm}$ was measured using a microplate reader (Bio-Rad Laboratories, Inc.).

Cell migration and invasion assays. The migration of $\mathrm{H} 9 \mathrm{c} 2$ cells was assessed by chamber migration assays, using two-chamber-Transwell 24-well cell culture plates (Corning, Inc.) with $8-\mu \mathrm{m}$ polycarbonate filters. Briefly, hypoxic injury was induced in $\mathrm{H} 9 \mathrm{c} 2$ cells as aforementioned, following treatment with ISC II where appropriate; the cells were then resuspended in $200 \mu \mathrm{l}$ serum-free media, and then seeded into the upper chambers of the inserts within a 24-well plate ( $1 \times 10^{5}$ cells/well); $500 \mu 1$ complete medium was added to the lower compartment as a chemoattractant. After culture for $48 \mathrm{~h}$ at $37^{\circ} \mathrm{C}$, the migrated cells in the lower chamber were fixed with ethanol, stained with crystal violet at room temperature for $5 \mathrm{~min}$, and counted under an inverted light microscope at $\mathrm{x} 200$ magnification (Olympus Corporation). For the invasion assays, the inserts were precoated with Matrigel (BD Biosciences) at room temperature for $1 \mathrm{~h}$. Each experiment was performed in triplicate.

Apoptosis assay. The percentage of apoptotic cells was measured using the FITC-Annexin V Apoptosis Detection kit (BD Bioscience) according to the manufacturer's instructions. The cells were analyzed using a FACScan flow cytometer (BD Bioscience) with FlowJo v10.0.7 software (Tree Star, Inc.).

$R N A$ purification and $R T-q P C R$. Total RNA was extracted from cells using TRIzol ${ }^{\circledR}$ reagent (Invitrogen; Thermo Fisher Scientific, Inc.) according to the manufacturer's instructions. Reverse transcription of the RNA was performed using the PrimeScript ${ }^{\mathrm{TM}} \mathrm{RT}$ reagent kit (Takara Biotechnology Co., Ltd.) and $\mathrm{qPCR}$ was performed with the TaqMan ${ }^{\mathrm{TM}}$ MicroRNA Reverse Transcription kit and TaqMan $^{\mathrm{TM}}$ Universal Master Mix (Applied Biosystems; Fisher Scientific, Inc.). GAPDH and U6 were used as internal controls for BTG2 and miR-7-5p, respectively. The reverse transcription primer for miR-7-5p was 5'-GTCGTATCCAGTGCAGGGTCCGAGGTGCAC TGGATACGACACAACAA-3'. The qPCR primers were as follows: miR-7-5p forward, 5'-TGGAAGACTAGTGATTTT-3' and reverse, 5'-CTCAACTGGTGTCGTG-3; BTG2 forward, 5'-CTGGAGGAGAACTGGCTGTC-3' and reverse, 5'-AAA ACAATGCCCAAGGTCTG-3'; U6 forward, 5'-GCTTCG GCAGCACATATACTAAAAT-3' and reverse, 5'-CGCTTC ACGAATTTGCGTGTCAT-3'; and GAPDH forward, 5'-TGA CCACAGTCCATGCCATC-3' and reverse, 5'-GACAAGCTT CCCGTTCTCAG-3'. The qPCR conditions were as following: $30 \mathrm{sec}$ at $94^{\circ} \mathrm{C}$, followed by 40 cycles of $5 \mathrm{sec}$ at $94^{\circ} \mathrm{C}, 10 \mathrm{sec}$ at $55^{\circ} \mathrm{C}, 10 \mathrm{sec}$ at $72^{\circ} \mathrm{C}$, and a final extension of $10 \mathrm{~min}$ at $72^{\circ} \mathrm{C}$. The expression levels in tissues and cells were calculated using the $2^{-\Delta \Delta \mathrm{Cq}} \operatorname{method}(17)$.

miRNA microarray analysis. Total cellular RNA was purified from cells cultured under hypoxic conditions using TRIzol ${ }^{\circledR}$ 
reagent and the RNeasy mini kit (Qiagen $\mathrm{GmbH})$ according to the manufacturer's instructions. The RNA samples were quantified using a NanoDrop spectrophotometer (NanoDrop Technologies; Thermo Fisher Scientific, Inc.), and then labeled using the miRCURY ${ }^{\mathrm{TM}} \mathrm{Hy}^{\mathrm{TM}} / \mathrm{Hy}^{\mathrm{TM}}$ Power labelling kit (Qiagen $\mathrm{GmbH}$ ). The labelled samples were hybridized to a microarray (NimbleGen Systems, Inc.) for 16-20 h, and the array sections were scanned using the GenePix 4000B microarray scanner (Axon Instruments). The results were read and analyzed using GenePix Pro V6.0 (Molecular Devices, LLC). A heat map diagram was used to display the data for two-way hierarchical clustering of genes and samples.

Bioinformatic analysis. TargetScan bioinformatics software (www.targetscan.org) was used to predict the potential target of miR-7-5p.

Dual-luciferase reporter assay. A BTG2 3'-unranslated region (UTR) cDNA fragment, which contained the miR-7-5p binding site, was subcloned into a pmirGIO dual luciferase miRNA target expression plasmid (Promega Corporation) to create a luciferase reporter vector (BTG2-wt). A BTG2 3'-UTR that was mutated at the miR-7-5p complementary site was generated (BTG2-mut) using the GeneArt ${ }^{\text {TM }}$ Site-directed Mutagenesis System (Thermo Fisher Scientific, Inc.) according to the manufacturer's instructions, and was also inserted into a pmirGIO reporter plasmid. H9c2 cells were subsequently co-transfected with the both reporter plasmid and miR-7-5p mimics or mimic NC, and luciferase activity was subsequently detected using the Dual-luciferase Reporter Assay system (Promega Corporation). Transfection was performed using Lipofectamine ${ }^{\circledR} 2000$ according to the manufacturer's protocol. Luciferase activity was measured $24 \mathrm{~h}$ after transfection and Renilla luciferase activity was used to normalize that of firefly luciferase.

Lactate dehydrogenase $(\mathrm{LDH})$ release detection. The release of LDH was measured using the LDH Cytotoxicity Assay kit (Beyotime Institute of Biotechnology) according to the manufacturer's instructions.

Western blot analysis. Total protein was extracted from cells using RIPA lysis buffer and quantified using the Caspase-3 Assay kit (Fluorometric) (both Beyotime Institute of Biotechnology). Equal amounts of protein $(20 \mu \mathrm{g})$ were resolved using $12 \%$ SDS-PAGE gels and then transferred onto PVDF membranes (EMD Millipore). After blocking with $5 \%$ skim milk, the membranes were incubated with primary antibodies overnight at $4^{\circ} \mathrm{C}$, which was followed by probing with ant-mouse IgG, HRP-linked antibody (cat. no. 7076) or anti-rabbit HRP-linked antibody (cat. no. 7074) (1:5,000, Cell Signaling Technology, Inc.) at room temperature for $1 \mathrm{~h}$. The protein bands were visualized using an ECL detection system (EMD Millipore), and the intensity of the protein bands was quantified using ImageJ Software (National Institutes of Health). The following primary antibodies were purchased from Cell Signaling Technology, Inc.: Bcl-2 (cat. no. 15071), Bax (cat. no. 14796), GAPDH (cat. no. 5174), caspase-3 (cat. no. 9662), caspase-9 (cat. no. 9502), phosphorylated (p)-PI3K (cat. no. 4228), PI3K (cat. no. 3011), p-Akt (cat. no. 9614) and Akt (cat. no. 2966). The BTG2 antibody (cat. no. ab85051) was purchased from Abcam. All primary antibodies were diluted at a ratio of 1:1,000 in 5\% BSA.

Statistical analysis. The data are presented as the means \pm standard deviation from three independent repeated experiments. Statistical analysis was performed using GraphPad 7.0 statistical software (GraphPad Software, Inc.), and the significant differences between groups were determined by one-way analysis of variance followed by Tukey's post hoc test. $\mathrm{P}<0.05$ was considered to indicate a statistically significant difference.

\section{Results}

Hypoxia induces myocardial injury in $\mathrm{H} 9 \mathrm{c} 2 \mathrm{cells}$. To produce a hypoxia-induced injury model, $\mathrm{H} 9 \mathrm{c} 2$ cells were exposed to hypoxic conditions for 4, 8, 12 and $24 \mathrm{~h}$, and cellular viability was assessed using the CCK-8 assay. As indicated in Fig. 1A, hypoxia reduced the viability of $\mathrm{H} 9 \mathrm{c} 2$ cells in a time-dependent manner. The levels of apoptosis were also detected following culture under hypoxic conditions for $24 \mathrm{~h}$ and were significantly increased when compared with those of the control group (Fig. 1B). These results were further supported by an LDH assay, which confirmed that hypoxia treatment significantly promoted LDH release (Fig. 1C). Furthermore, compared with the control, hypoxia treatment led to the downregulation of the anti-apoptotic protein Bcl-2, and upregulation of the proapoptotic protein Bax; the cleavage of caspase- 3 and -9 was also observed following exposure to hypoxic conditions (Fig. 1D). The migration and invasion abilities of H9c2 cells were also significantly decreased following culture under hypoxic conditions (Fig. 1E and F). Therefore, it was confirmed that hypoxia results in damage to $\mathrm{H} 9 \mathrm{c} 2$ cells, and that an in vitro hypoxia cell model was successfully generated.

ICS II protects $H 9 c 2$ cells from hypoxia-induced injury. The effects of ICS II on hypoxia-induced injury in H9c2 cells were investigated. To determine a suitable dosage, cells were incubated with various concentrations of ICS II (2, 4 and $8 \mu \mathrm{M}$ ) for $24 \mathrm{~h}$, and cell viability was then assessed. As shown in Fig. 2A, there were no significant differences in cell viability among cells treated with different concentrations of ICS II. As 2-8 $\mu \mathrm{M}$ exerted neither pro- nor anti-survival effects on $\mathrm{H} 9 \mathrm{c} 2$ cells under normoxic conditions, $8 \mu \mathrm{M}$ was selected as the dose of ICS II for subsequent experiments.

The protective effects of ICS II on H9c2 cells under hypoxic conditions were then investigated. CCK-8 assay results indicated that the hypoxia-induced decrease in cell viability was notably mitigated by ICS II pretreatment $(\mathrm{P}<0.01$; Fig. 2B). Similarly, the hypoxia-induced increase in apoptosis was significantly reversed ( $\mathrm{P}<0.001$; Fig. $2 \mathrm{C}$ ), and hypoxia-induced LDH release was significantly inhibited $(\mathrm{P}<0.01$; Fig. 2D) by ICS II pretreatment. Western blot analysis revealed that hypoxia induced alterations in Bax, Bcl-2, cleaved caspase- 3 and -9 , and that these results were significantly reversed by ICS II treatment (P<0.05; Fig. 2E). Furthermore, ICS II treatment markedly increased the migration and invasion capacities of $\mathrm{H} 9 \mathrm{c} 2$ cells under hypoxic conditions (Fig. 2F and G). These data indicate that ICS II 

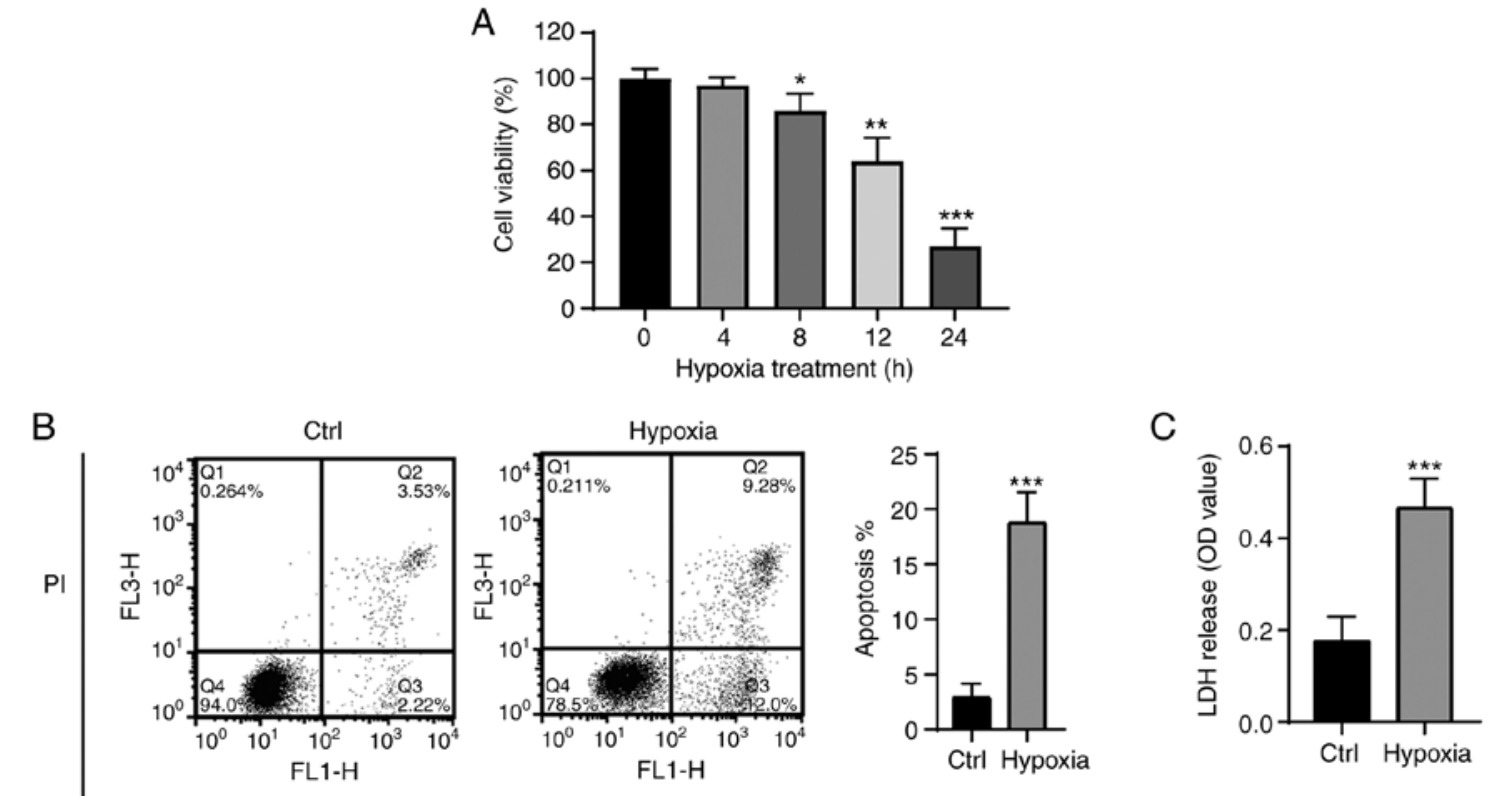

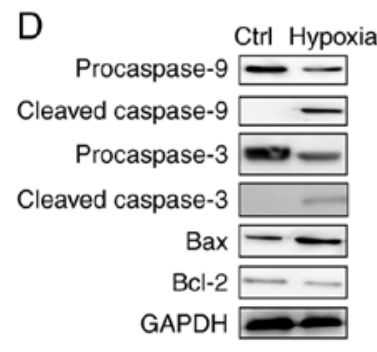

E

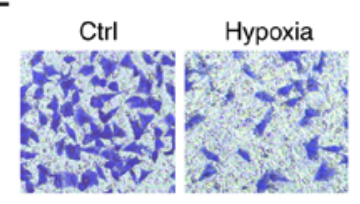

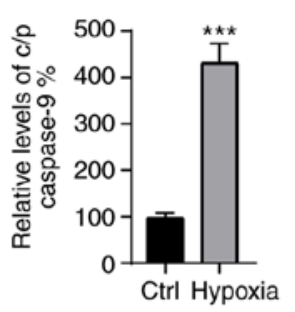

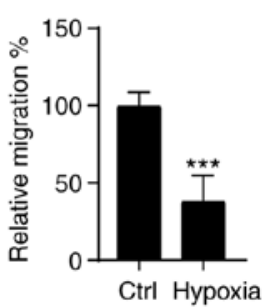

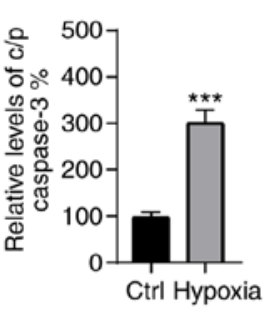

$\mathrm{F}$

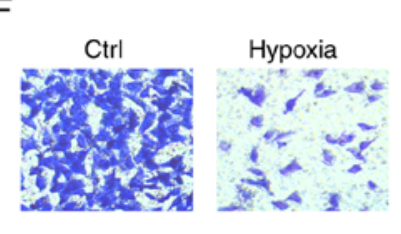

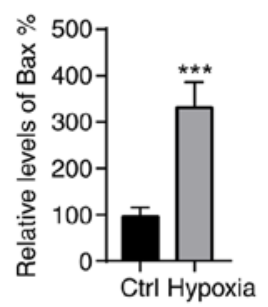
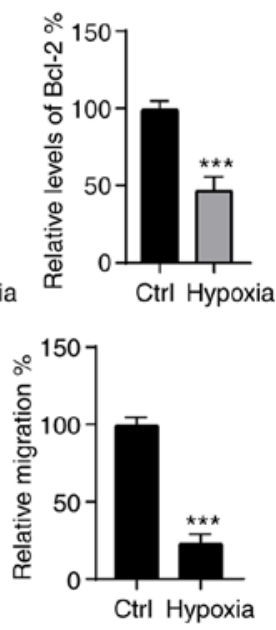

Figure 1. Hypoxia-induced injury in H9c2 cells. (A) H9c2 cells were exposed to hypoxic conditions as indicated, and cell viability was measured using the Cell Counting Kit 8 assay. H9c2 cells were incubated under hypoxic conditions for $24 \mathrm{~h}$, and (B) the percentage of apoptotic cells and (C) LDH release was measured. (D) Expression levels of the indicated proteins were measured by western blotting $24 \mathrm{~h}$ after culture in hypoxic conditions. (E) Migration and (F) invasion capacities of $\mathrm{H} 9 \mathrm{c} 2$ cells under thypoxic conditions. Data are presented as the mean $\pm \mathrm{SD}$ of three independent experiments. ${ }^{*} \mathrm{P}<0.05$, $^{* *} \mathrm{P}<0.01$ and ${ }^{* * *} \mathrm{P}<0.001$. LDH, lactate dehydrogenase; Ctrl, control.

provides protection against hypoxia-associated injury in H9c2 cells.

ICS II attenuates hypoxia-induced injury in H9c2 cells by upregulating miR-7-5p expression. An miRNA chip array was used to determine whether the protective effects of ICS II were exerted via the regulation of miRNAs. In total, 11 upregulated and 11 downregulated miRNAs were identified following ICS II treatment of H9c2 cells under hypoxic conditions, of which miR-7-5p was the most upregulated (Fig. 3A). The levels of miR-7-5p following ICS II treatment were then verified using RT-qPCR. The results showed that treatment with ICS II markedly increased miR-7-5p expression (Fig. 3B), indicating the involvement of miR-7-5p in the protective effects of ICS II. To investigate the role of miR-7-5p in this setting, miR-7-5p mimics and inhibitors were transfected into H9c2 cells. As indicated in Fig. 3C, miR-7-5p levels were significantly increased following transfection with miR-7-5p mimics $(\mathrm{P}<0.001)$, and notably decreased by the miR-7-5p inhibitor $(\mathrm{P}<0.01)$ compared with the control cells. The transfected cells were then treated with ICS II prior to exposure to hypoxic conditions. The effects of ICS II pretreatment were significantly abrogated by inhibiting miR-7-5p, which is indicated by decreased cell viability $(\mathrm{P}<0.01$; Fig. 3D), increased apoptosis $(\mathrm{P}<0.01$; Fig. 3E) and increased $\mathrm{LDH}$ release $(\mathrm{P}<0.001$; Fig. 3F). Conversely, miR-7-5p mimics enhanced the protective effects of ICS II, showing increased cell viability $(\mathrm{P}<0.001$; Fig. $3 \mathrm{C})$, decreased apoptosis $(\mathrm{P}<0.01$; Fig. 3E) and decreased $\mathrm{LDH}$ release $(\mathrm{P}<0.05$; Fig. 3F). Moreover, western blot analysis confirmed that the protective effect of ICS II against hypoxia-induced injury relied on the upregulation of miR-7-5p (Fig. 3G), since 

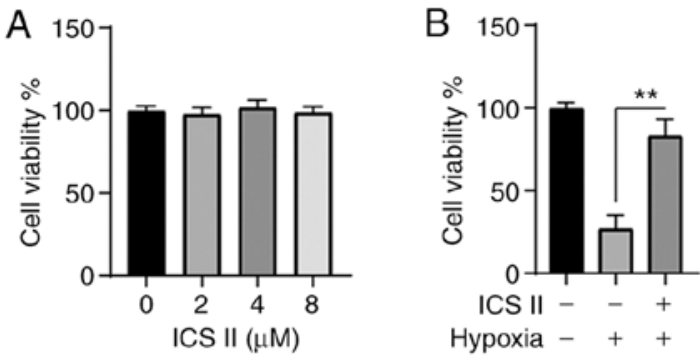

C
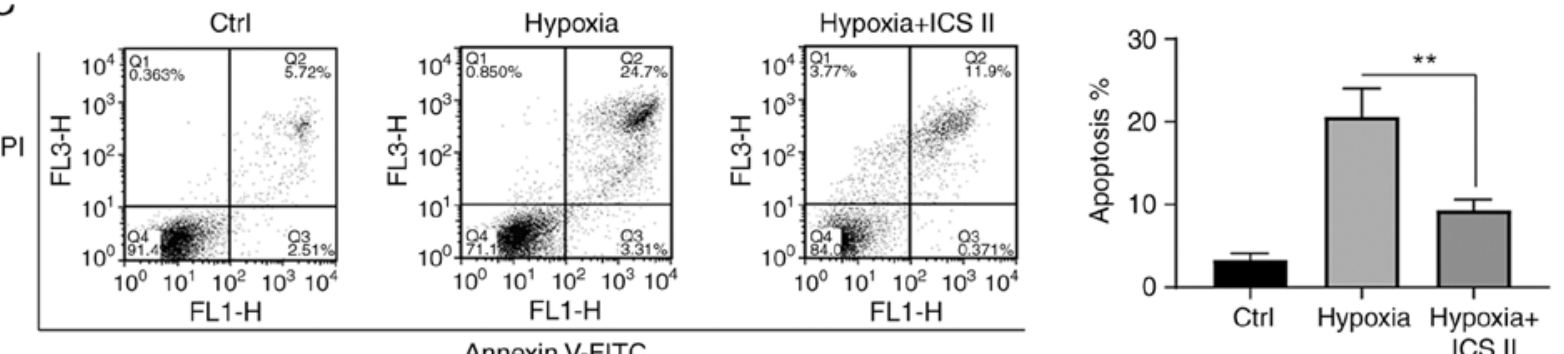

Annexin V-FITC
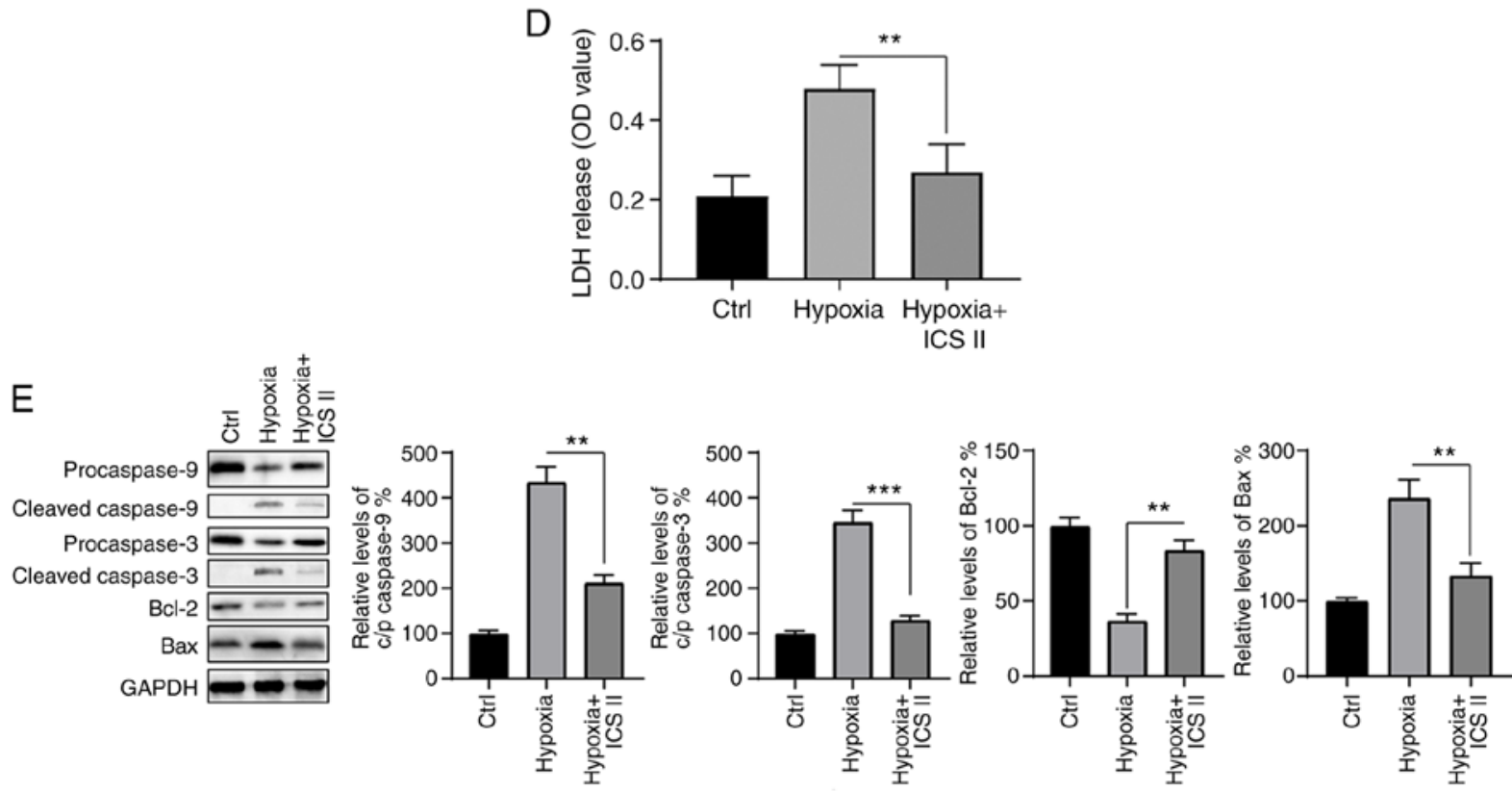

$\mathrm{F}$
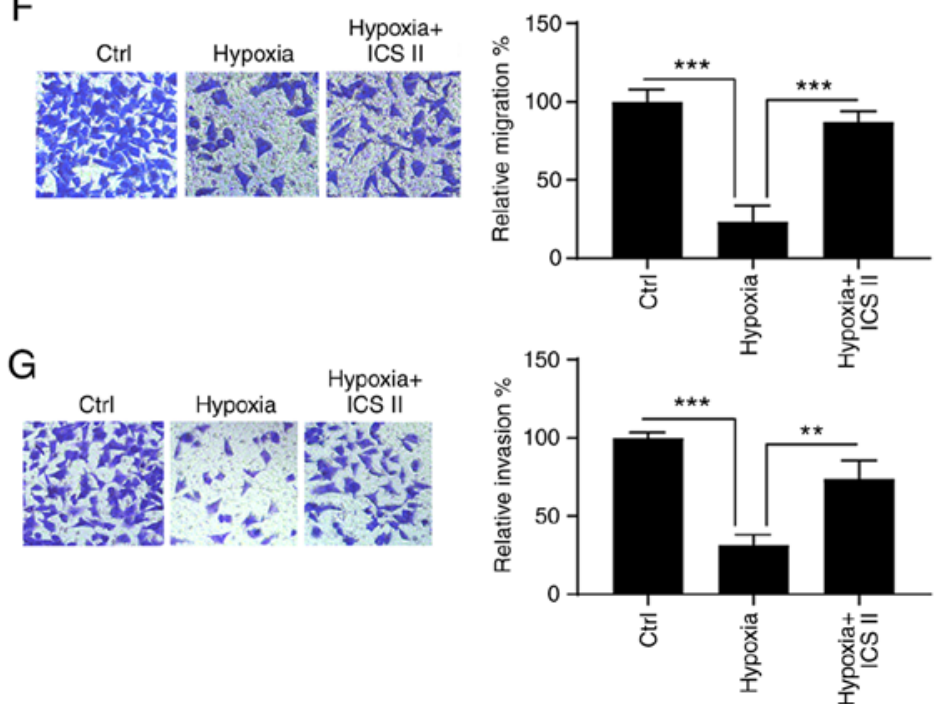

Figure 2. ICS II attenuates hypoxia-induced H9c2 cell injury. (A) H9c2 cells were treated with ICS II as indicated, and cell viability was assessed. H9c2 cells were pretreated with $8 \mu \mathrm{M}$ ICS II for $24 \mathrm{~h}$, followed by hypoxia for another $24 \mathrm{~h}$; (B) cell viability and (C) apoptosis were that quantified, and (D) LDH release was detected. (E) Expression levels of the indicated proteins were measured by western blotting, and (F) migration and (G) invasion capacity was determined Data are presented as the mean $\pm \mathrm{SD}$ of three independent experiments. ${ }^{* *} \mathrm{P}<0.01$ and ${ }^{* * *} \mathrm{P}<0.001$. ICS II, Icariside II; LDH, lactate dehydrogenase; Ctrl, control. 
A
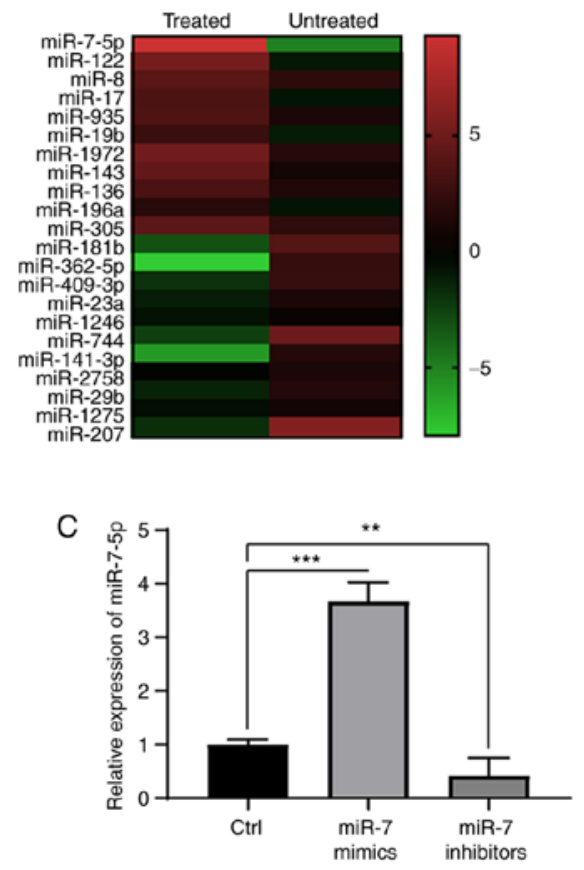

B

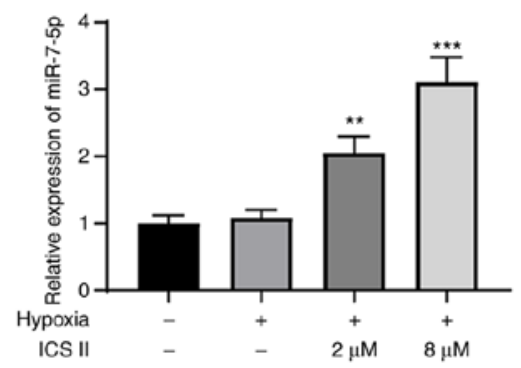

D

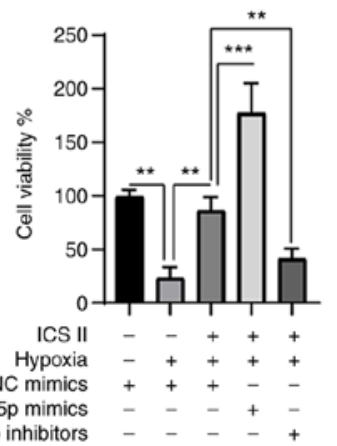

$E$

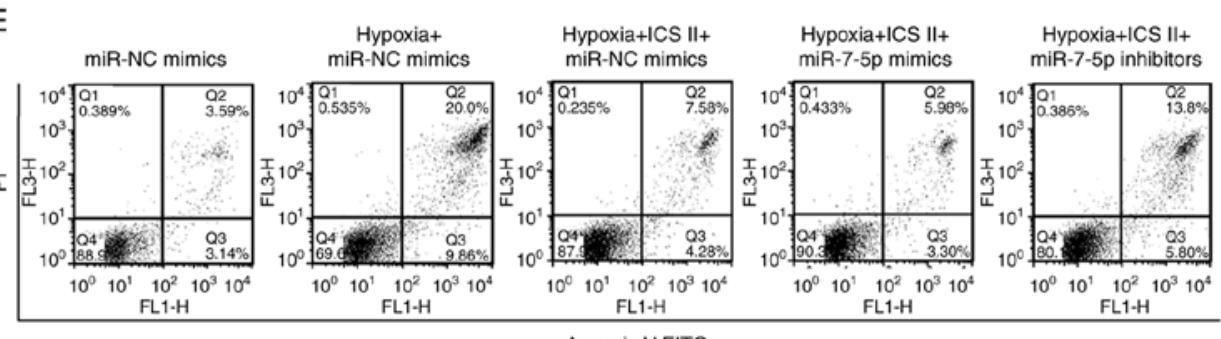

Annexin V-FITC

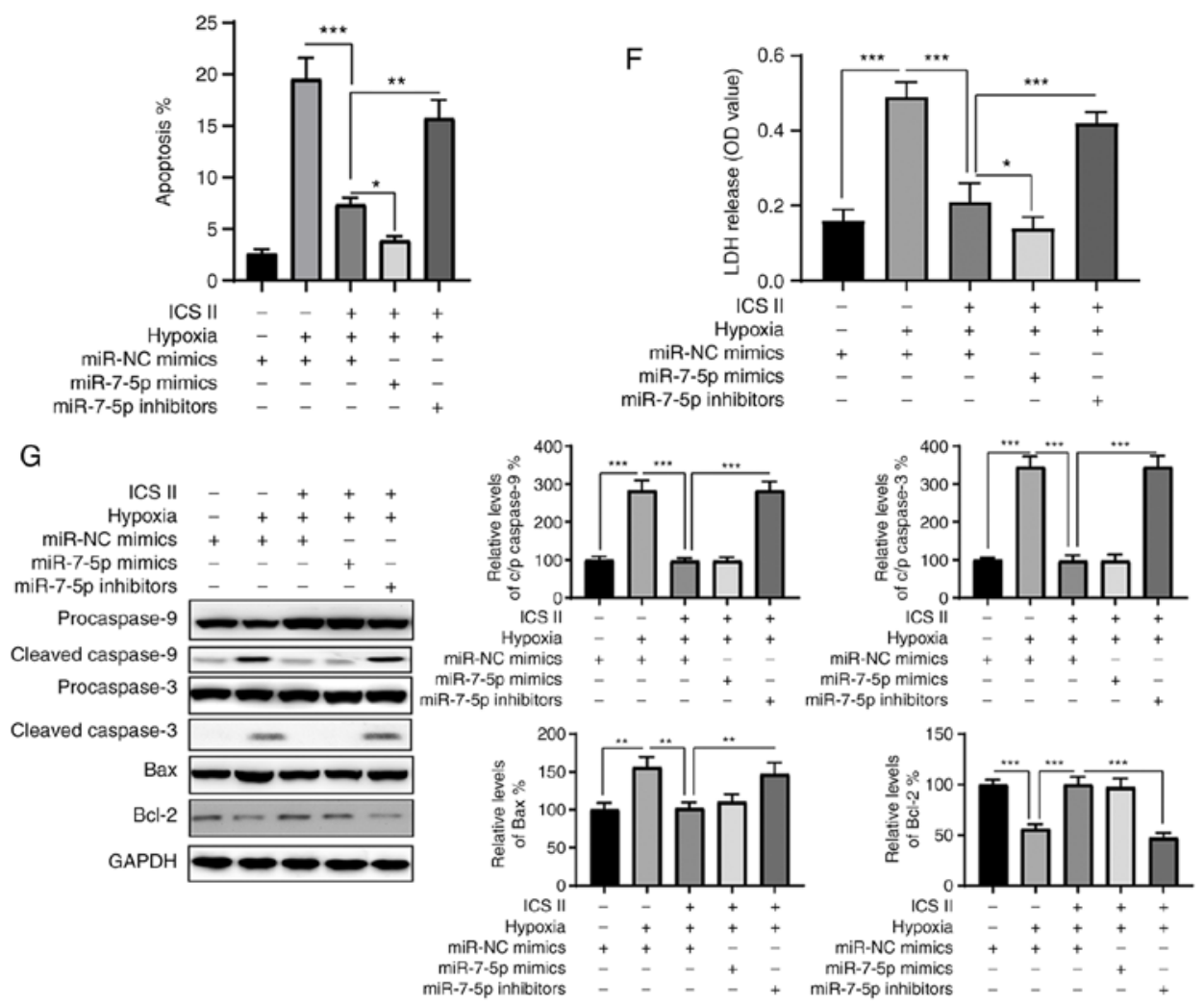

Figure 3. ICS II pretreatment affects hypoxia-treated H9c2 cells via the upregulation of miR-7-5p. (A) Heat map of miRNA chip array analysis of H9c2 cells treated with ICS II vs. PBS-treated controls. Upregulated (red) and downregulated (green) miRNAs; P $\leq 0.05$. (B) H9c2 cells were exposed to hypoxic conditions and treated with ICS II as indicated; the expression levels of miR-7-5p were then determined. (C) H9c2 cells were transfected as indicated and the levels of miR-7-5p were determined. H9c2 cells were treated as indicated and (D) viability, (E) apoptosis and (F) LDH release were analyzed. (G) Protein expression levels were evaluated by western blot analysis. 

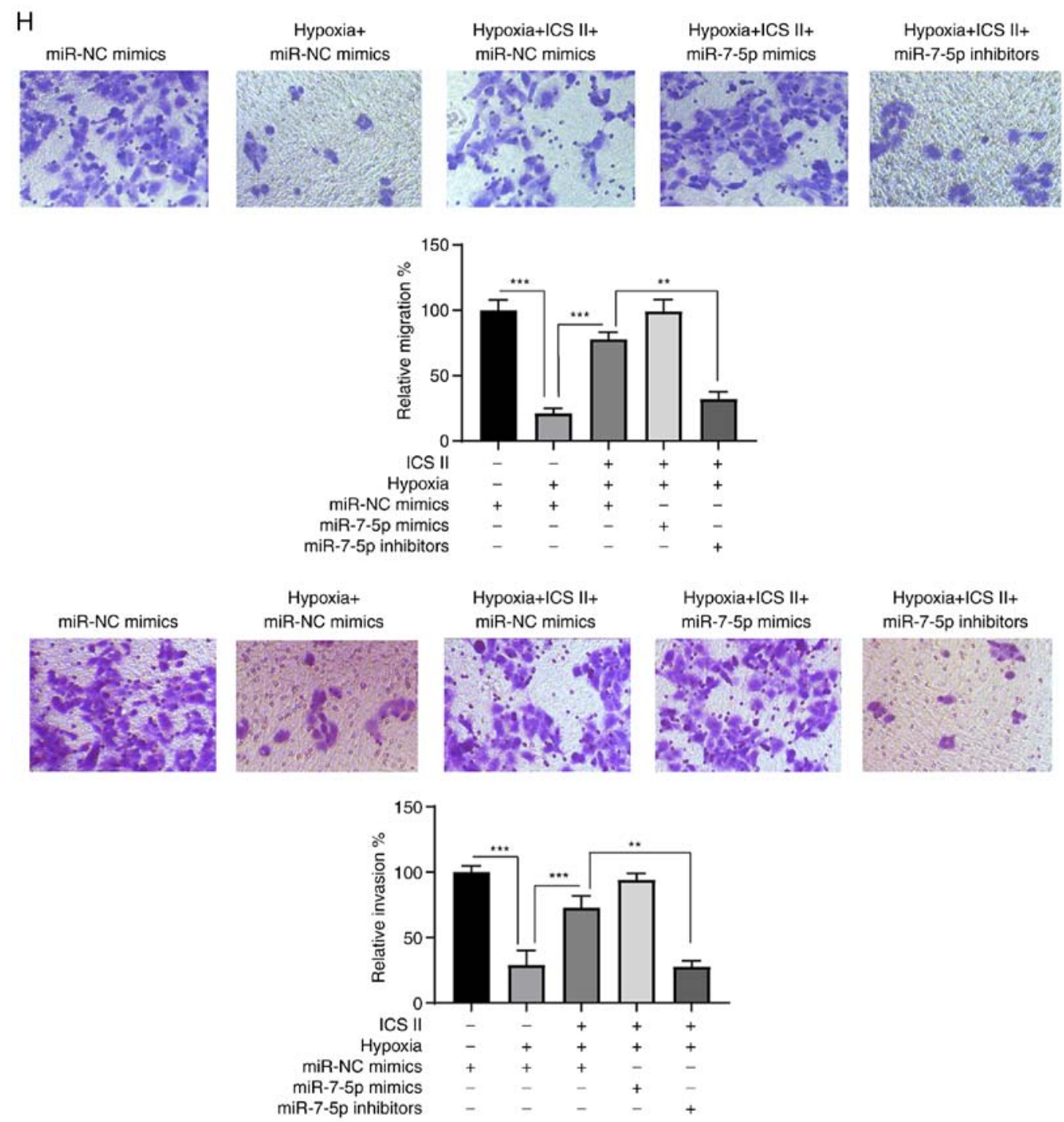

Figure 3. Continued. (H) migration and invasion capacity were assayed. Data are presented as the mean $\pm \mathrm{SD}$ of three independent experiments. " $\mathrm{P}<0.05$, ${ }_{* * *} \mathrm{P}<0.01$ and ${ }^{* * *} \mathrm{P}<0.001$. ICS II, Icariside II; miR/miRNA, micro RNA; NC, negative control; LDH, lactate dehydrogenase; Ctrl, control.

caspase-3 cleavage was rescued by inhibiting miR-7-5p in the presence of ICS II under hypoxic conditions. ICS II was also demonstrated to restore the migration and invasive capacities of $\mathrm{H} 9 \mathrm{c} 2$ cells under hypoxic conditions via miR-7-5p, since inhibition of miR-7-5p blocked this effect (Fig. 3H). These data indicate that ICS II provides protective effects against hypoxia in $\mathrm{H} 9 \mathrm{c} 2$ cells, at least partly via the upregulation of miR-7-5p.

miR-7-5p directly targets BTG2, which reverses the effect of miR-7-5p on H9c2 cells exposed to hypoxic conditions. Using TargetScan, BTG2 was identified as a potential target for miR-7-5p (Fig. 4A, left). Luciferase reporter assays confirmed the association between miR-7-5p and BTG2 (Fig. 4B); the luciferase activity of BTG2-wt was significantly inhibited in miR-7-5p-transfected cells, while that of the BTG2-mut remained unaltered. Furthermore, the mRNA and protein levels of BTG2 were significantly decreased and increased in the miR-7-5p mimic and inhibitor groups, respectively (Fig. 4B and C). These observations suggest a negative regulatory relationship between miR-7-5p and BTG2.
BTG2 was then ectopically expressed to investigate whether miR-7-5p affected hypoxia-induced injury in $\mathrm{H} 9 \mathrm{c} 2$ cells via the regulation of BTG2. As indicated in Fig. 4D, western blot analysis showed that the protein level of BTG2 was successfully overexpressed in H9c2 cells via transfection with pcDNA3.1 BTG2 $(\mathrm{P}<0.001)$. Further experiments revealed that the effects of miR-7-5p on migration and invasion under hypoxic conditions were blocked by BTG2 overexpression (Fig. 4E). Functional experiments indicated that miR-7-5p overexpression retained cell viability $(\mathrm{P}<0.001$; Fig. $4 \mathrm{~F})$, reduced apoptosis $(\mathrm{P}<0.001$; Fig. $4 \mathrm{G})$, reduced $\mathrm{LDH}$ release $(\mathrm{P}<0.001$; Fig. 4H), downregulated cleaved caspase-3/ -9 and pro-apoptotic Bax, and upregulated Bcl-2 (Fig. 4I) in hypoxia-treated cells. However, the effects of miR-7-5p overexpression on cells treated under hypoxic conditions were obviously abrogated by BTG 2 overexpression $(\mathrm{P}<0.001$; Fig. $4 \mathrm{~F}-\mathrm{I})$. These results indicate that the overexpression of BTG2 reverses the effect of miR-7-5p on hypoxia-treated H9c2 cells.

BTG2 knockdown protects $H 9 \mathrm{c} 2$ cells from hypoxia-induced injury. To further confirm the role of BTG2 in the protective 
A

BTG2 wt: 5'guuuuuuggccaaaacUCUUCCu 3'

miR-7 : 3’uguuguuuuagugaucAGAAGGu 5

H朴 BTG2 wt: 5'guuuuuuggccaaaacAGCAGAu 3'

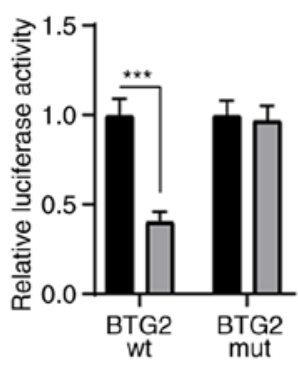

C
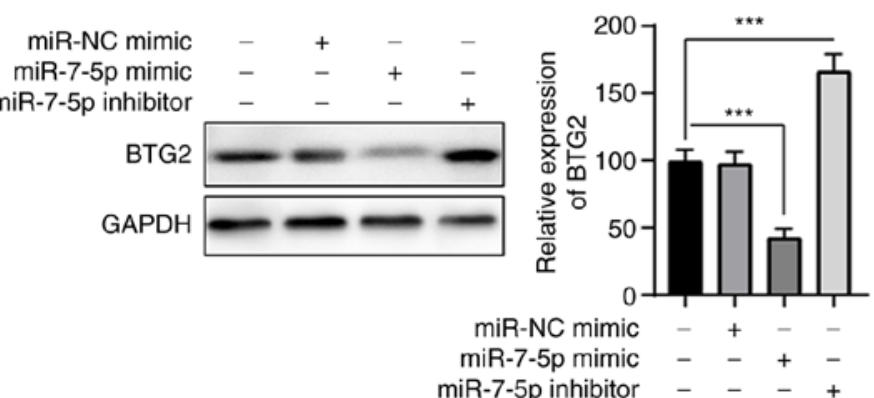

$E$
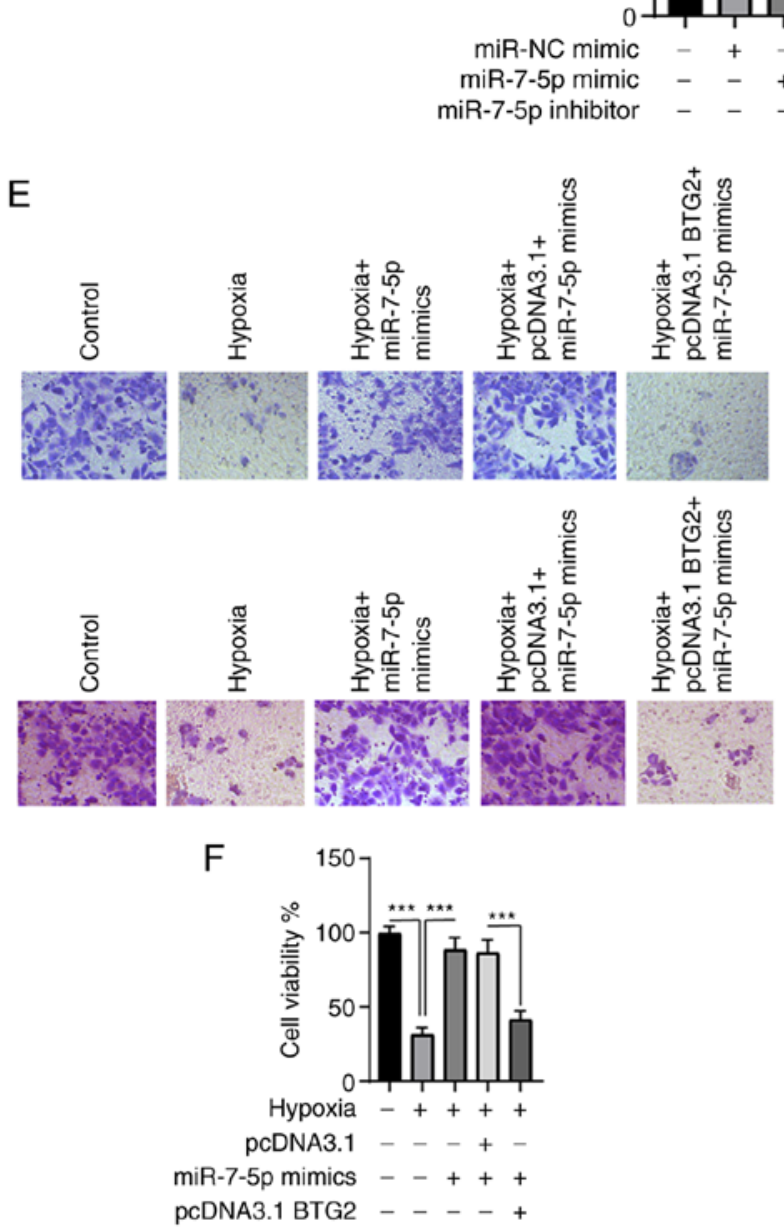
miR-7-5p mimic
B

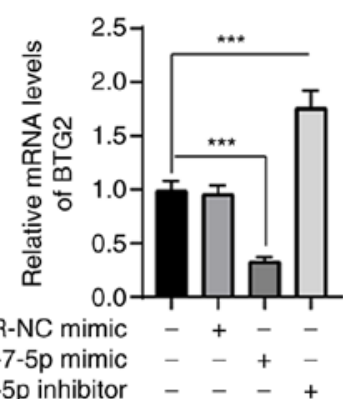
miR-7-5p inhibitor
D
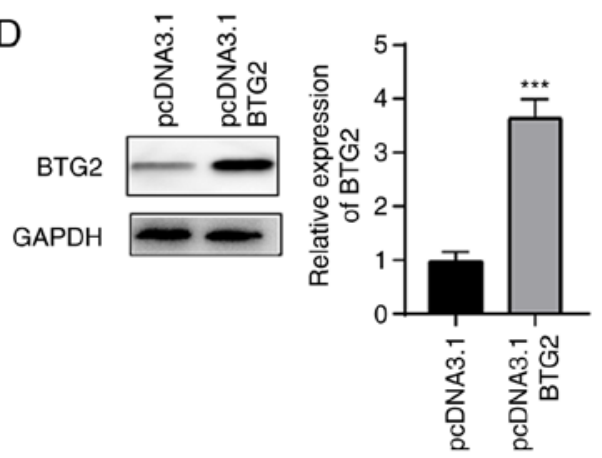
GAPDH
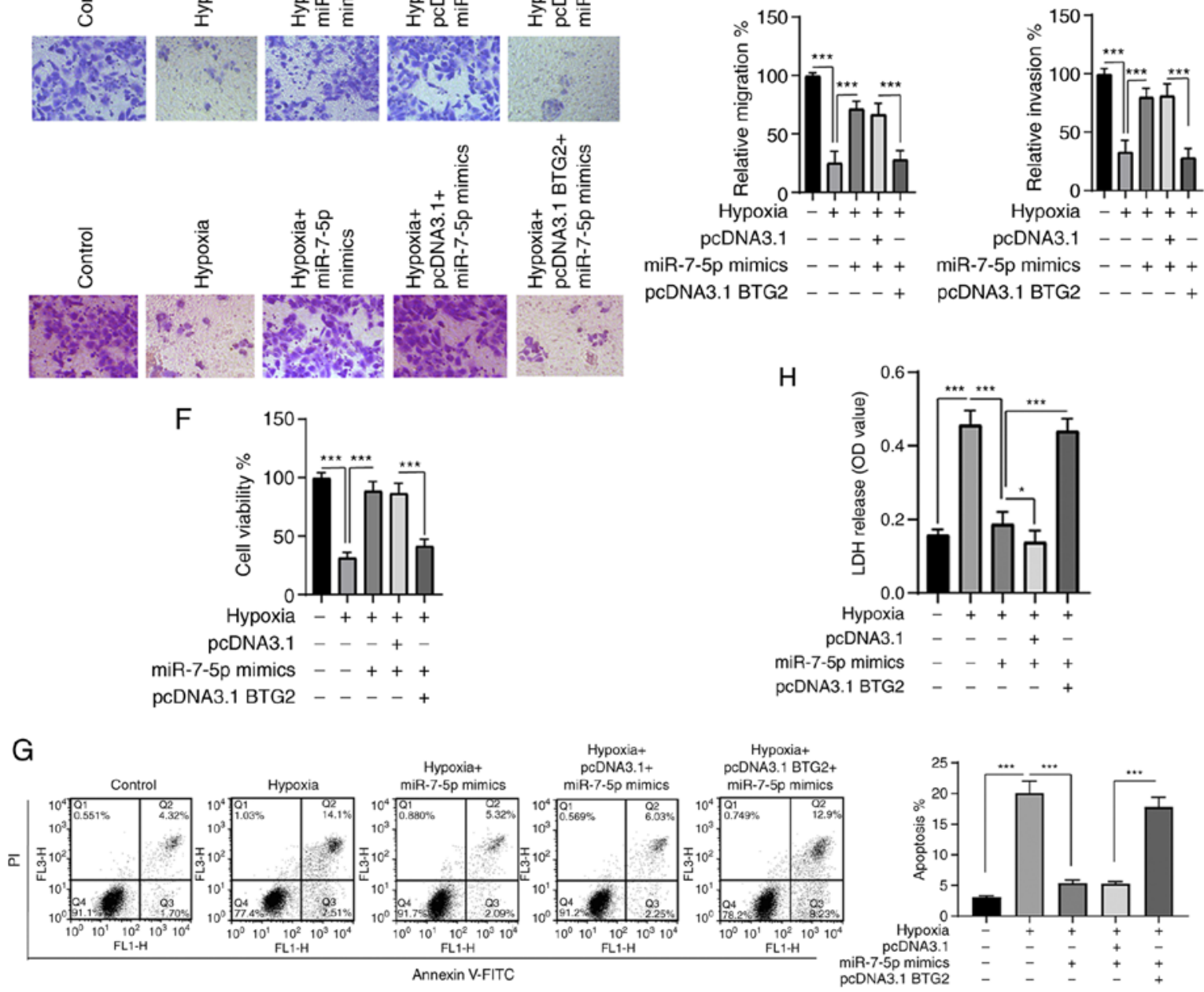

Figure 4. BTG2 is a direct target of miR-7-5p. (A) The putative binding site between BTG2 and miR-7-5p was predicted and the association was analyzed by dual luciferase reporter assay. After transfection, the (B) mRNA and (C) protein expression levels of BTG2 were measured using reverse transcription-quantitative PCR and western blotting, respectively. (D) H9c2 cells were transfected as indicated, and the protein levels of BTG2 were measured by western blotting. Cells were treated as indicated, and (E) migration and (F) invasion capacities were assayed. Cells were treated as indicated, and the (F) viability, $(\mathrm{G})$ rates of apoptosis and $(\mathrm{H})$ release of $\mathrm{LDH}$ were assayed. 

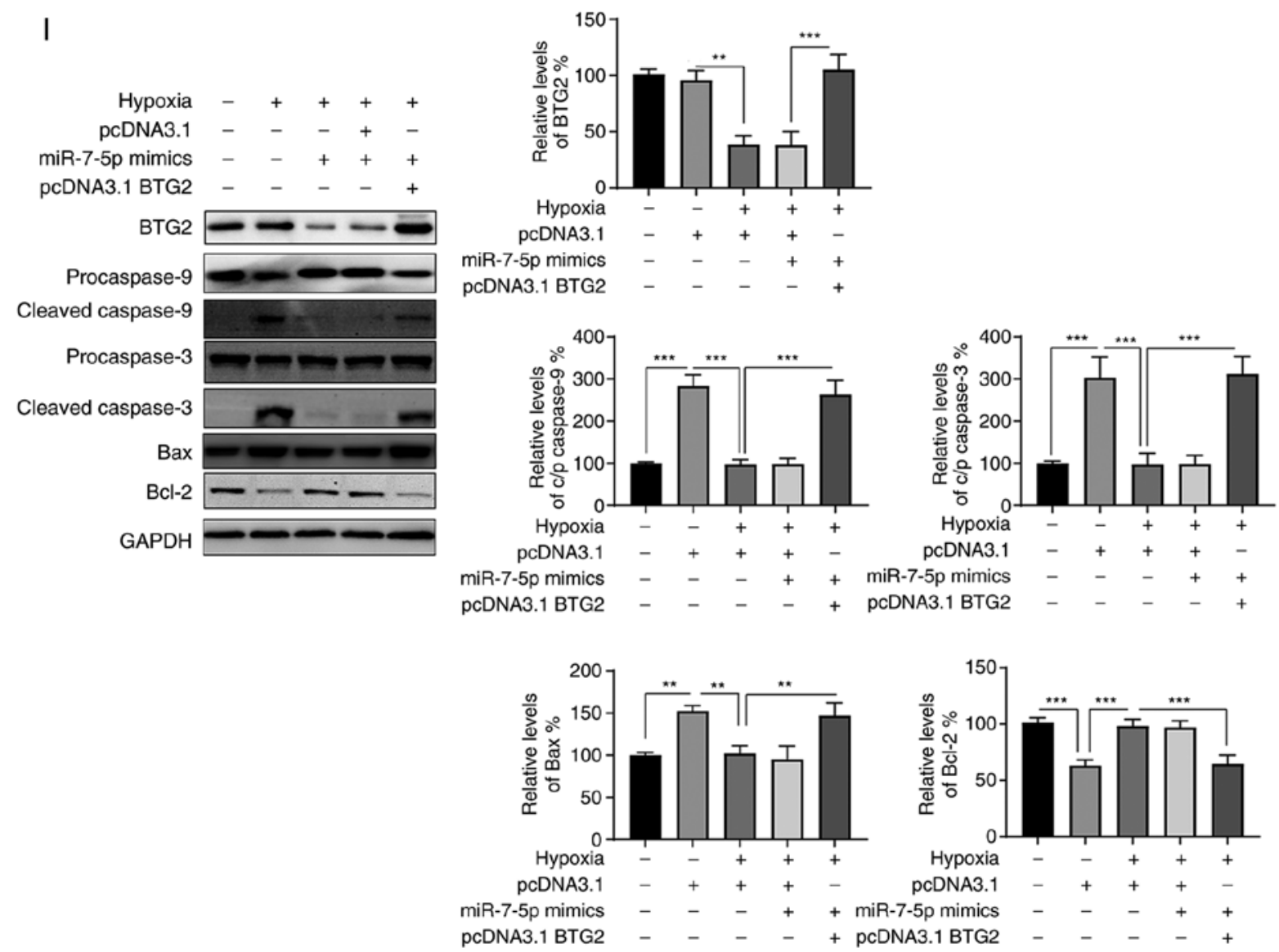

Figure 4. Continued. (I) Total cellular lysates were subjected to the western blot analysis. Data are presented as the mean \pm SD of three independent experiments. ${ }^{*} \mathrm{P}<0.05,{ }^{* * *} \mathrm{P}<0.01$ and ${ }^{* * * *} \mathrm{P}<0.001$. BTG2, BTG anti-proliferation factor; miR/miRNA, micro RNA; WT, wild type; MUT, mutant; LDH, lactate dehydrogenase.

effects of ICS II, siRNAs were used to knock down BTG2 in H9c2 cells. As indicated in Fig. 5A, two siRNAs targeting BTG2 (siBTG2 \#1 and \#2) were transfected into H9c2 cells for $24 \mathrm{~h}$, which resulted in a significant decrease in BTG2 expression compared with the control group (siCtrl); $24 \mathrm{~h}$ post-transfection, H9c2 cells were exposed to hypoxic conditions for another $24 \mathrm{~h}$, and cell viability was assayed. BTG2 knockdown under hypoxic conditions markedly enhanced the viability of H9c2 cells compared with that of the control group (Fig. 5B). Moreover, knockdown of BTG2 successfully reduced apoptosis and LDH release caused by hypoxia (Fig. 5C and D). In addition, western blotting also confirmed that the activation of caspase-3 and -9 , the downregulation of Bcl-2 and the upregulation of Bax caused by hypoxia were reversed by BTG2 knockdown. Knocking down BTG2 also restored the migration and invasion abilities of $\mathrm{H} 9 \mathrm{c} 2$ cells under hypoxic conditions (Fig. 5F). Taken together, these data suggest that BTG2 may be an important regulator in hypoxia-induced injury of $\mathrm{H} 9 \mathrm{c} 2$ cells.

ICS II exerts its protective effect by activating the PI3K/Akt signaling pathway. Mounting evidence indicates that the PI3K/Akt signaling pathway plays an essential protective role in cardiomyoblasts. Therefore, the potential effects of ICS II on the PI3K/Akt signaling pathway were investigated. As indicated in Fig. 5A, p-PI3K and p-Akt levels were notably decreased in $\mathrm{H} 9 \mathrm{c} 2$ cells exposed to hypoxic condi- tions, compared with those of the control group; there was little change in the levels of total PI3K and Akt. Treatment with ICS II or overexpression of miR-7-5p mimics restored the expression of $\mathrm{p}-\mathrm{PI} 3 \mathrm{~K}$ and $\mathrm{p}-\mathrm{Akt}$, indicating the activation of the PI3K/Akt signaling pathway (Fig. 6A). However, the phosphorylation levels of PI3K and Akt were decreased in the presence of hypoxia, ICS II and miR-7-5p inhibitor combined (Fig. 6A). These findings indicate that ICS II activates the PI3K/Akt signaling pathway via the upregulation of miR-7-5p under hypoxic conditions. To further investigate the function of the PI3K/Akt signaling pathway in the protective effect of ICS II, cells were treated with LY294002, a specific PI3K/Akt inhibitor. As shown in Fig. 6B, LY294002 successfully inhibited the activation of the PI3K/Akt signaling pathway. LY294002 also abrogated the protective effects of ICS II on the viability of H9c2 cells under hypoxic conditions (Fig. 6C). LY249002 also promoted apoptosis and the release of $\mathrm{LDH}$, which was induced by hypoxia in the presence of ICS II (Fig. 6D and E). Moreover, the activation of caspase-3 and -9, a decrease in Bcl-2 and an increase in Bax caused by hypoxia were also caused by LY294002 (Fig. 6F). Furthermore, the effects of ICS II on the migration and invasion of H9c2 cells under hypoxic conditions could be blocked by LY294002 (Fig. 6G). Collectively, these data suggest that ICS II treatment activates the PI3K/Akt signaling pathway, which is essential for the survival of $\mathrm{H} 9 \mathrm{c} 2$ cells under hypoxic conditions. 


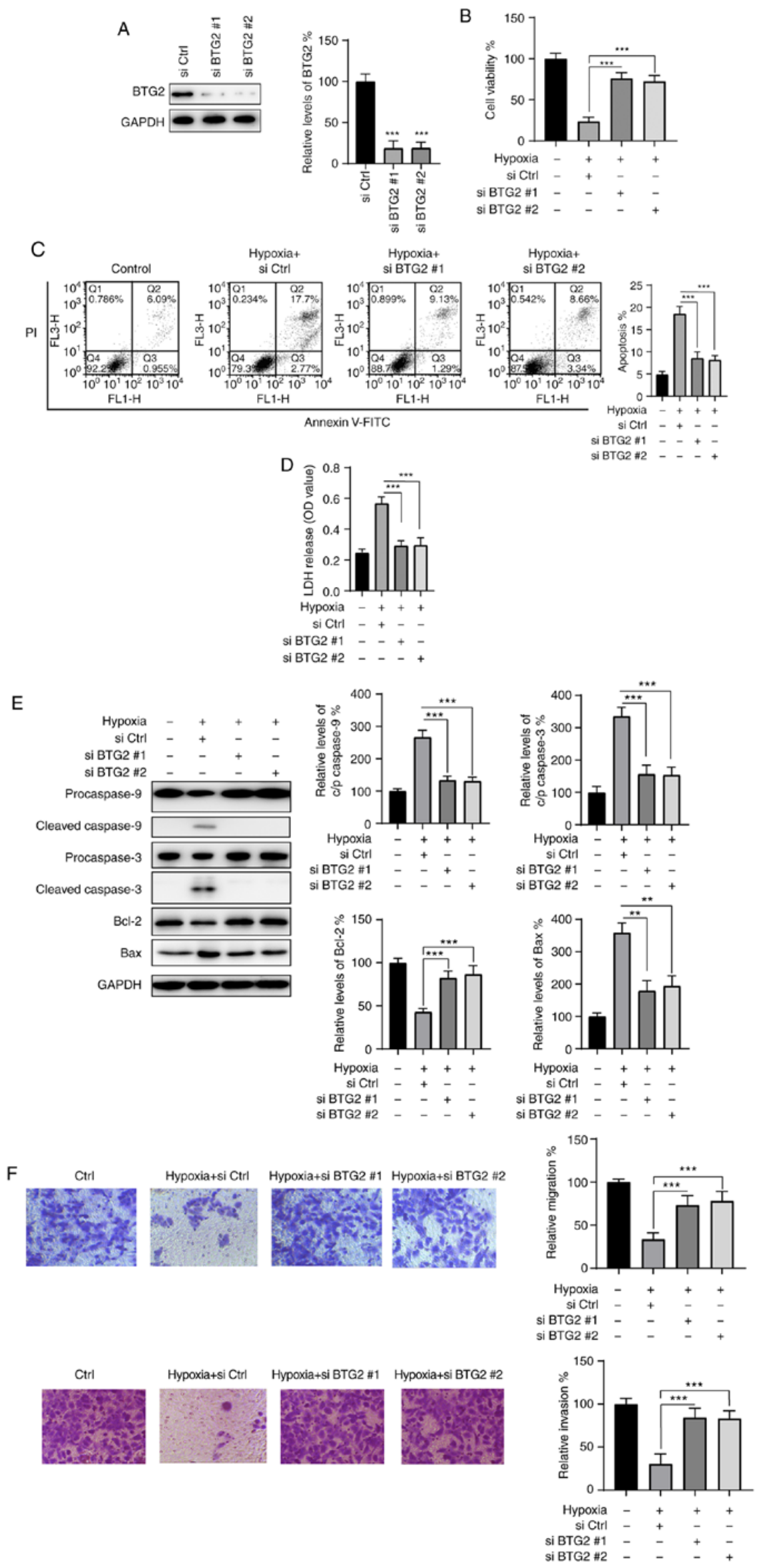

Figure 5. BTG2 knockdown exerts protective effects against hypoxia-induced injury. (A) H9c2 cells were transfected with siRNA against BST2 for $24 \mathrm{~h}$, and the protein levels of BTG2 were measured by western blotting. (B) Cellular viability, (C) apoptosis and (D) LDH release were also assessed. (E) Total cellular lysates were subjected to western blot analysis with the indicated antibodies. (F) Migration and invasion capacities were determined. Data are presented as the mean \pm SD of three independent experiments. ${ }^{* *} \mathrm{P}<0.01$ and ${ }^{* * *} \mathrm{P}<0.001$. BTG2, BTG anti-proliferation factor; si, short interfering; LDH, lactate dehydrogenase; Ctrl, control. 

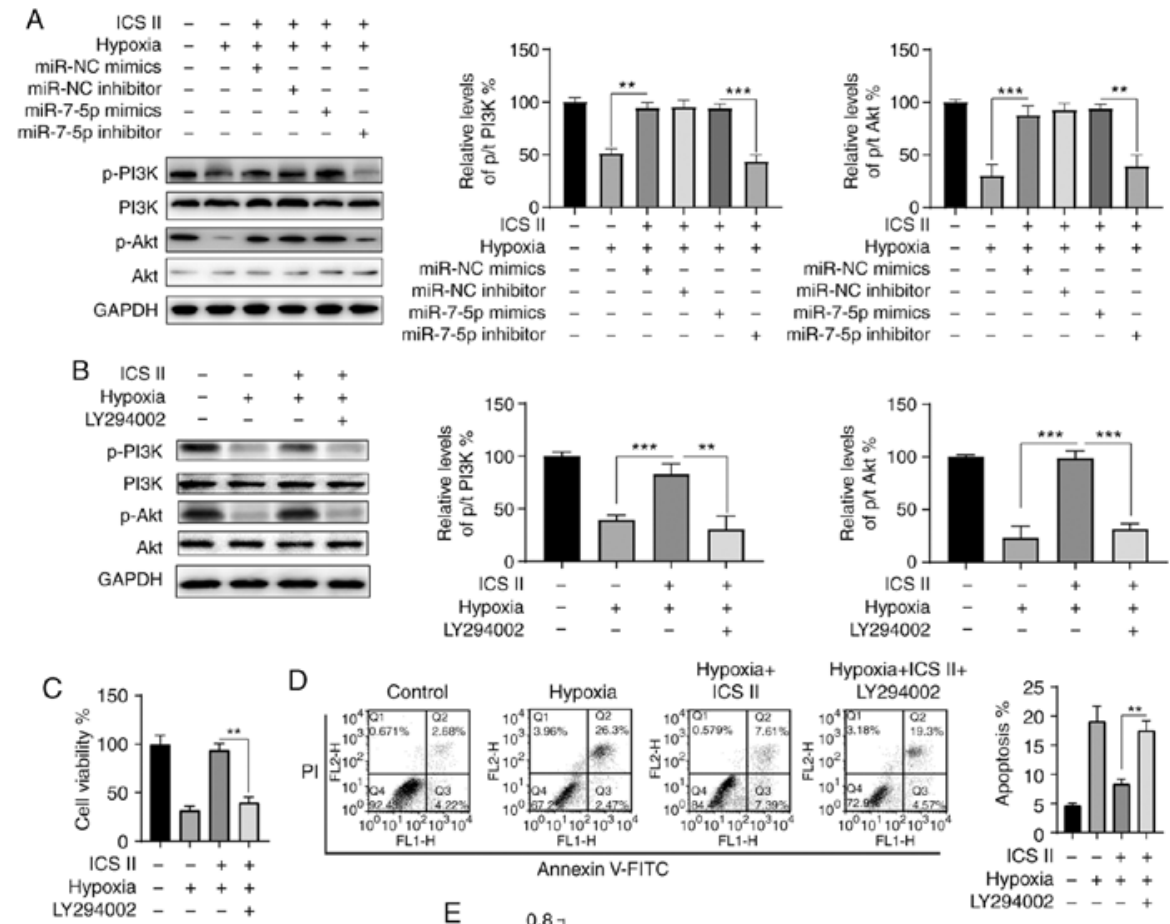

D Control Hypoxia Hypoxia+

Hypoxia+ICS II+
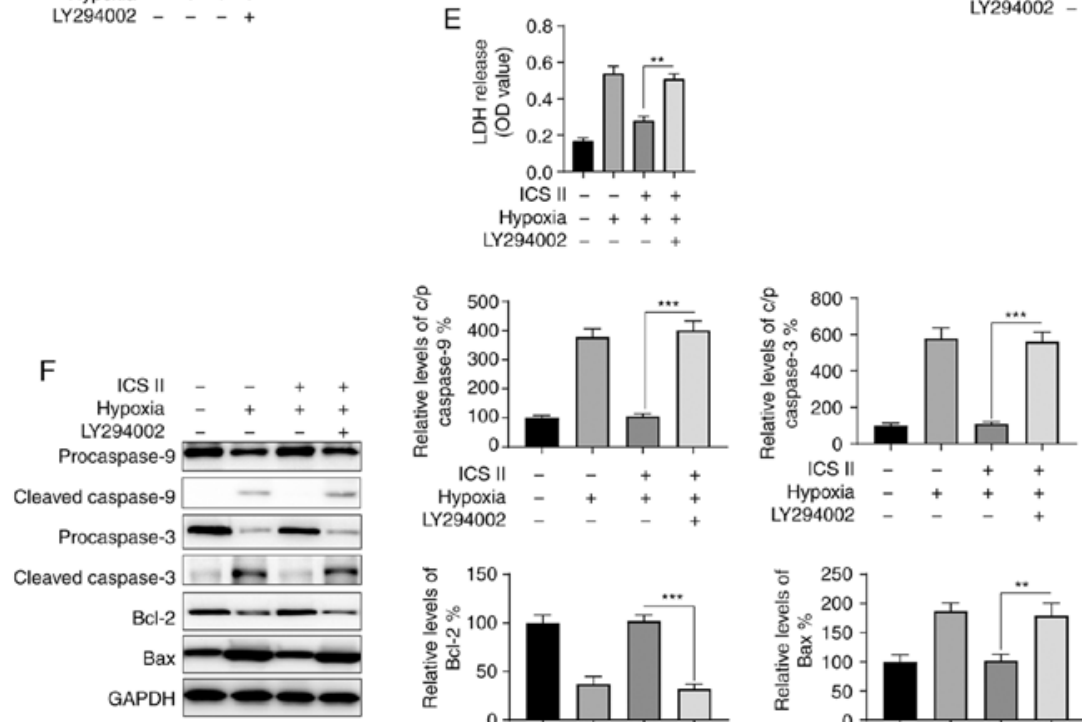

G
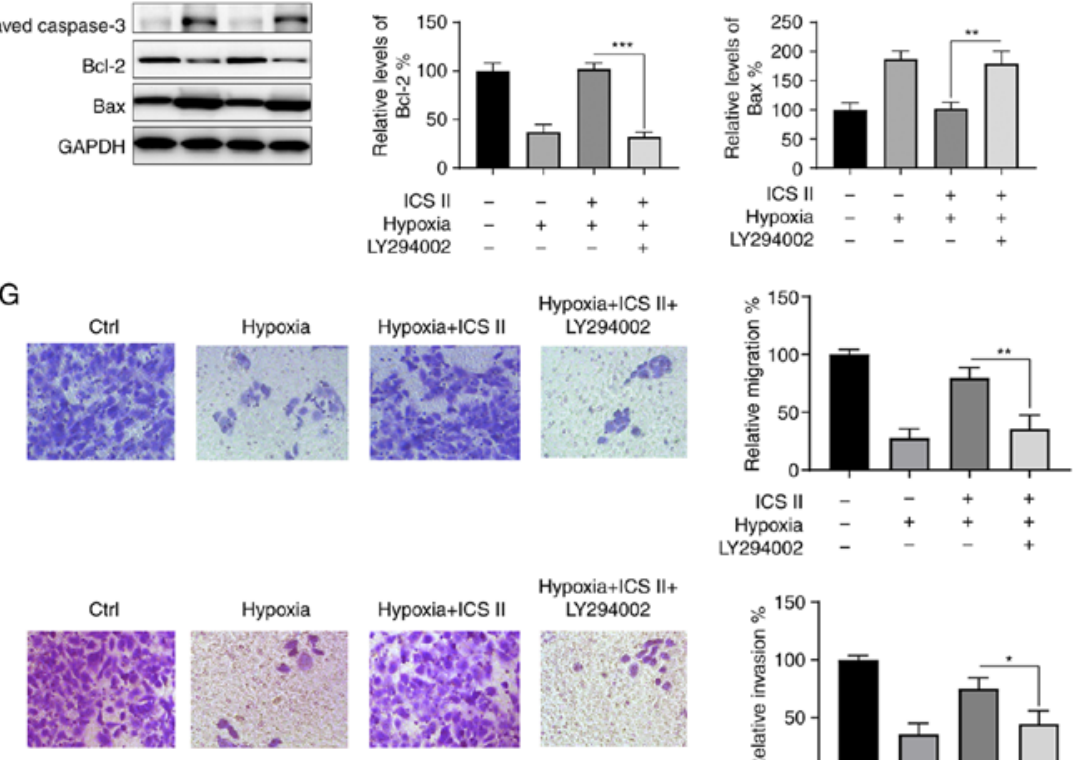

Hypoxia+ICS II+
LY294002
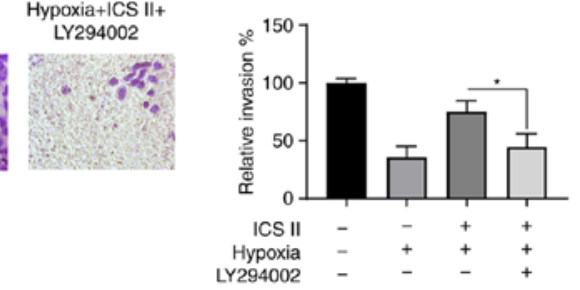

Figure 6. ICS II activates PI3K/Akt signaling in H9c2 cells via the upregulation of miR-7-5p. (A) and (B) H9c2 cells were transfected as indicated, and total cellular lysates were subjected to western blot analysis. H9c2 cells were treated as indicated, then total cellular lysates were subjected to western blot analysis. (C) Cell viability, (D) apoptosis and (E) LDH release were assayed and (F) total cellular lysates were subjected to western blot analysis. (G) migration and invasiveness of cells were also assayed. Data are presented as the mean \pm SD of three independent experiments. ${ }^{*} \mathrm{P}<0.05,{ }^{* * *} \mathrm{P}<0.01$ and ${ }^{* * * *} \mathrm{P}<0.001$. ICS II, Icariside II; miR/miRNA, micro RNA; NC, negative control; LDH, lactate dehydrogenase; Ctrl, control. 


\section{Discussion}

In the present study, the protective effects of ICS II on hypoxia-induced cardiomyocyte injury were investigated, as well as the potential underlying molecular mechanisms. Hypoxic exposure was found to markedly decrease the viability of rat $\mathrm{H} 9 \mathrm{c} 2$ cardiomyocytes and to induce apoptosis. ICS II protected $\mathrm{H} 9 \mathrm{c} 2$ cells against hypoxia-induced apoptosis and a loss in viability by upregulating the expression of miR-7-5p. In addition, BTG2 was identified as a direct target of miR-7-5p, and its overexpression abrogated the protective effects of miR-7-5p in a hypoxia-induced injury model. Furthermore, ICS II was also shown to activate the PI3K/Akt signaling pathway, which is essential for the survival of $\mathrm{H} 9 \mathrm{c} 2$ cells under hypoxic conditions.

ICS II is a flavonol glycoside isolated from Herba Epimedii that has been found to exhibit antitumor, anti-inflammatory, neuroprotective and antidiabetic activities (18-20). However, there are few reports about the effects of ICS II on hypoxia-induced cell injury. A previous study showed that ICS II could attenuate myocardial fibrosis by inhibiting the NF-kB and transforming growth factor- $\beta 1 / \mathrm{Smad} 2$ signaling pathways (8). Another study indicated that ICS II ameliorated diabetic cardiomyopathy in streptozotocin-induced diabetic rats (9). However, the effects of ICS II on hypoxic-induced cardiomyocyte injury remained elusive. In the present study, hypoxia-induced injury was significantly abrogated by ICS II, presenting with increased viability and reduced apoptosis. In line with previous studies, these findings further confirmed the cardioprotective effects of ICS II.

To elucidate the potential underlying molecular mechanisms of ICS II protection on hypoxia-induced H9c2 cell injury, the relationship between ICS II and miR-7-5p was investigated in hypoxia-treated $\mathrm{H} 9 \mathrm{c} 2$ cells. miR-7-5p is a miRNA that is evolutionarily conserved from parasites to mammals. miR-7-5p has been found to act as a tumor suppressor in various types of cancer, such as bladder cancer, pancreatic cancer and melanoma (21-23). Only a few studies have investigated the functions of miR-7-5p in cardiomyopathy, but it has been found to protect cardiomyocytes from I/R-induced injury (16). In addition, a recent study also revealed that the inhibition of miR-7-5p contributed to myocardial I/R injury (24). In line with these reports, the present study revealed that inhibiting miR-7-5p expression notably reversed the protective effects of ICS II in a hypoxia-induced $\mathrm{H} 9 \mathrm{c} 2$ cell injury model.

BTG2 is a member of the BTG/TOB gene family (25) that BTG2 has been identified as a tumor suppressor in various cancer types (26). A previous study found that the downregulation of BTG2 via miR-21 could protect cardiomyocytes against doxorubicin-induced apoptosis (27). In the present study, bioinformatics and luciferase gene reporter assays showed that BTG2 was a direct target of miR-7-5p in H9c2 cells. Moreover, BTG2 reversed the protective effect of miR-7-5p on hypoxia-induced injury in H9c2 cells. In addition, BTG2 knockdown emulated the effects of ICS II treatment by providing protective effects to $\mathrm{H} 9 \mathrm{c} 2$ cells against hypoxia-induced injury. These findings indicate that BTG2 may be an important regulator in MI, and that the effect of ICS II on the expression of miR-7-5p may also rely on the regulation of BTG2. Notably, it was also found that hypoxia treatment could lead to the upregulation of BTG2 (28); therefore, further studies are required to further investigate the role of BTG2 in hypoxia.

An abundance of evidence has shown that activation of the PI3K/Akt pathway is able to protect the heart from I/R injury, as well as enhance the survival of cardiomyocytes $(29,30)$. Consistent with the findings of the present study, ICS II activated the Akt signaling pathway and thereby exerted protective effects on osteoblasts (31). However, another study reported that ICS II inhibited the PI3K/Akt signaling pathway in non-small cell lung cancer cells. From the results of the present study, it was proposed that ICS II is able to both activate and inhibit the PI3K/Akt signaling pathway depending on the cell type involved, though further study is required to confirm this hypothesis. In line with a previous study, miR-7-5p was also shown to trigger the activation of the PI3K/Akt signaling pathway (32). Notably, in another recent study, it was shown that silencing BTG2 contributed to the activation of the $\mathrm{PI} 3 \mathrm{~K} / \mathrm{Akt}$ pathway, which is in accordance with the findings of the present study (33).

To the best of our knowledge, the present study was the first to investigate the effects of ICS II on hypoxia-treated $\mathrm{H} 9 \mathrm{c} 2$ cells. The results revealed an in vitro protective effect of ICS II on cardiomyocytes. The present study also revealed that miR-7-5p was a downstream factor responsive to ICS II, and that ICS II may protect $\mathrm{H} 9 \mathrm{c} 2$ cells from hypoxia-induced injury via the upregulation of miR-7-5p. Furthermore, BTG2 was identified as a direct target gene of miR-7-5p, and BTG2 overexpression reversed the effects of miR-7-5p on hypoxia-treated H9c2 cells, while BTG2s knockdown provided protective effects. Finally, the present study demonstrated that ICS II treatment also led to the activation of the PI3K/Akt pathway, which is essential for the survival of H9c2 cells under hypoxic conditions. More clinical and/or in vivo experimentation is required to support these findings.

\section{Acknowledgements}

Not applicable.

\section{Funding}

The present study was supported by the key fund of the Jiangxi Science and Technology Bureaucracy (grant no. 20171BBG70016).

\section{Availability of data and materials}

The datasets used and/or analyzed during the current study are available from the corresponding author on reasonable request.

\section{Authors' contributions}

DH was involved in the conception of the study and writing the original manuscript draft. YG was involved in study conception and design, and critical revision of the manuscript. DW was involved in study conception and design, and data acquisition. JZ, QL and JL analyzed and interpreted the data and drafted the manuscript. SL took part in data acquisition and revising the manuscript for important intellectual content. 
ZY and BZ took part in study conception and design, as well as supervision, project administration, funding acquisition and writing (reviewing and editing). All authors read and approved the final manuscript.

\section{Ethics approval and consent to participate}

Not applicable.

\section{Patient consent for publication}

Not applicable.

\section{Competing interests}

The authors declare that they have no competing interests.

\section{References}

1. Townsend N, Wilson L, Bhatnagar P, Wickramasinghe $\mathrm{K}$, Rayner $\mathbf{M}$ and Nichols M: Cardiovascular disease in Europe: Epidemiological update 2016. Eur Heart J 37: 3232-3245, 2016.

2. Yellon DM and Hausenloy DJ: Myocardial reperfusion injury. N Engl J Med 357: 1121-1135, 2007.

3. Graham RM, Frazier DP, Thompson JW, Haliko S, Li H, Wasserlauf BJ, Spiga MG, Bishopric NH and Webster KA: A unique pathway of cardiac myocyte death caused by hypoxia-acidosis. J Exp Biol 207: 3189-3200, 2004.

4. Kemp CD and Conte JV: The pathophysiology of heart failure. Cardiovasc Pathol 21: 365-371, 2012.

5. Ambrosy AP, Fonarow GC, Butler J, Chioncel O, Greene SJ, Vaduganathan M, Nodari S, Lam CSP, Sato N, Shah AN and Gheorghiade M: The global health and economic burden of hospitalizations for heart failure: Lessons learned from hospitalized heart failure registries. J Am Coll Cardiol 63: 1123-1133, 2014.

6. Xie F, Wu CF, Lai WP, Yang XJ, Cheung PY, Yao XS, Leung PC and Wong MS: The osteoprotective effect of Herba epimedi (HEP) extract in vivo and in vitro. Evid Based Complement Alternat Med 2: 353-361, 2005.

7. Chen M, Wu J, Luo Q, Mo S, Lyu Y, Wei Y and Dong J: The anticancer properties of Herba epimedii and its main bioactive componentsicariin and icariside II. Nutrients 8: E563, 2016.

8. Fu S, Li YL, Wu YT, Yue Y, Qian ZQ and Yang DL: Icariside II attenuates myocardial fibrosis by inhibiting nuclear factor- $\kappa \mathrm{B}$ and the TGF- $\beta 1 / \mathrm{Smad} 2$ signalling pathway in spontaneously hypertensive rats. Biomed Pharmacother 100: 64-71, 2018.

9. Yang L, Peng C, Xia J, Zhang W, Tian L, Tian Y, Yang X and Cao Y: Effects of icariside II ameliorates diabetic cardiomyopathy in streptozotocin-induced diabetic rats by activating Akt/NOS/NF-кB signaling. Mol Med Rep 17: 4099-4105, 2018.

10. Alvarez-Garcia I and Miska EA: MicroRNA functions in animal development and human disease. Development 132: 4653-4662, 2005.

11. Bartel DP: MicroRNAs: Genomics, biogenesis, mechanism, and function. Cell 116: 281-297, 2004

12. Boon RA and Dimmeler S: MicroRNAs in myocardial infarction. Nat Rev Cardiol 12: 135-142, 2015.

13. Gu Y, Liang Z, Wang H, Jin J, Zhang S, Xue S, Chen J, He H, Duan K, Wang J, et al: Tanshinone IIA protects H9c2 cells from oxidative stress-induced cell death via microRNA-133 upregulation and Akt activation. Exp Ther Med 12: 1147-1152, 2016.

14. Jiang $\mathrm{G}, \mathrm{Wu} \mathrm{H}, \mathrm{Hu} \mathrm{Y}, \mathrm{Li}$ J and $\mathrm{Li} \mathrm{Q}$ : Gastrodin inhibits glutamate-induced apoptosis of PC12 cells via inhibition of CaMKII/ASK-1/p38 MAPK/p53 signaling cascade. Cell Mol Neurobiol 34: 591-602, 2014.

15. Kalinowski FC, Brown RA, Ganda C, Giles KM, Epis MR, Horsham $\mathrm{J}$ and Leedman PJ: microRNA-7: A tumor suppressor miRNA with therapeutic potential. Int J Biochem Cell Biol 54: 312-317, 2014.
16. Li B, Li R, Zhang C, Bian HJ, Wang F, Xiao J, Liu SW, Yi W, Zhang MX, Wang SX, et al: MicroRNA-7a/b protects against cardiac myocyte injury in ischemia/reperfusion by targeting poly(ADP-ribose) polymerase. PLoS One 9: e90096, 2014.

17. Livak KJ and Schmittgen TD: Analysis of relative gene expression data using real-time quantitative PCR and the 2(-Delta Delta C(T)) method. Methods 25: 402-408, 2001.

18. Song J, Feng L, Zhong R, Xia Z, Zhang L, Cui L, Yan H, Jia X and Zhang Z: Icariside II inhibits the EMT of NSCLC cells in inflammatory microenvironment via down-regulation of Akt/NF- $\mathrm{BB}$ signaling pathway. Mol Carcinog 56: 36-48, 2017.

19. Khan M, Maryam A, Qazi JI and Ma T: Targeting apoptosis and multiple signaling pathways with icariside II in cancer cells. Int J Biol Sci 11: 1100-1112, 2015.

20. Gao J, Deng Y, Yin C, Liu Y, Zhang W, Shi J and Gong Q: Icariside II, a novel phosphodiesterase 5 inhibitor, protects against $\mathrm{H}_{2} \mathrm{O}_{2}$-induced PC12 cells death by inhibiting mitochondria-mediated autophagy. J Cell Mol Med 21: 375-386, 2017.

21. Li J, Qiu M, An Y, Huang J and Gong C: miR-7-5p acts as a tumor suppressor in bladder cancer by regulating the hedgehog pathway factor Gli3. Biochem Biophys Res Commun 503: 2101-2107, 2018.

22. Zhu W, Wang Y, Zhang D, Yu X and Leng X: MiR-7-5p functions as a tumor suppressor by targeting SOX18 in pancreatic ductal adenocarcinoma. Biochem Biophys Res Commun 497: 963-970, 2018.

23. Giles KM, Brown RA, Ganda C, Podgorny MJ, Candy PA, Wintle LC, Richardson KL, Kalinowski FC, Stuart LM, Epis MR, et al: microRNA-7-5p inhibits melanoma cell proliferation and metastasis by suppressing RelA/NF- $\kappa \mathrm{B}$. Oncotarget 7: 31663-31680, 2016.

24. Zou L, Ma X, Lin S, Wu B, Chen Y and Peng C: Long noncoding RNA-MEG3 contributes to myocardial ischemia-reperfusion injury through suppression of miR-7-5p expression. Biosci Rep 39: BSR20190210, 2019.

25. Buanne P, Corrente G, Micheli L, Palena A, Lavia P, Spadafora C, Lakshmana MK, Rinaldi A, Banfi S, Quarto M, et al: Cloning of PC3B, a novel member of the PC3/BTG/TOB family of growth inhibitory genes, highly expressed in the olfactory epithelium. Genomics 68: 253-263, 2000.

26. Yuniati L, Scheijen B, van der Meer LT and van Leeuwen FN: Tumor suppressors BTG1 and BTG2: Beyond growth control. J Cell Physiol 234: 5379-5389, 2019.

27. Tong Z, Jiang B, Wu Y, Liu Y, Li Y, Gao M, Jiang Y, Lv Q and Xiao X: MiR-21 protected cardiomyocytes against doxorubicin-induced apoptosis by targeting BTG2. Int J Mol Sci 16: $14511-14525,2015$.

28. Leszczynska KB, Foskolou IP, Abraham AG, Anbalagan S, Tellier C, Haider S, Span PN, O'Neill EE, Buffa FM and Hammond EM: Hypoxia-induced p53 modulates both apoptosis and radiosensitivity via AKT. J Clin Invest 125: 2385-2398, 2015.

29. Bell RM and Yellon DM: Bradykinin limits infarction when administered as an adjunct to reperfusion in mouse heart: The role of PI3K, Akt and eNOS. J Mol Cell Cardiol 35: 185-193, 2003.

30. Keyes KT,Xu J,Long B,Zhang C,HuZ Zand Ye Y: Pharmacological inhibition of PTEN limits myocardial infarct size and improves left ventricular function postinfarction. Am J Physiol Heart Circ Physiol 298: H1198-H1208, 2010.

31. Liu W, Mao L, Ji F, Chen F, Wang S and Xie Y: Icariside II activates EGFR-Akt-Nrf2 signaling and protects osteoblasts from dexamethasone. Oncotarget 8: 2594-2603, 2017.

32. Liu ML, Zhang Q, Yuan X, Jin L, Wang LL, Fang TT and Wang WB: Long noncoding RNA RP4 functions as a competing endogenous RNA through miR-7-5p sponge activity in colorectal cancer. World J Gastroenterol 24: 1004-1012, 2018.

33. Xu Z, Wang Y, Xiong J, Cui F, Wang L and Peng H: NUSAP1 knockdown inhibits cell growth and metastasis of non-small-cell lung cancer through regulating BTG2/PI3K/Akt signaling. J Cell Physiol 235: 3886-3893, 2019.

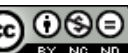

This work is licensed under a Creative Commons Attribution-NonCommercial-NoDerivatives 4.0 International (CC BY-NC-ND 4.0) License. 